\title{
VER JUGAR. EL VAIVÉN DE LA TRASCENDENCIA DEPORTIVA
}

SEE PLAYING. THE TRASCENDENCY SPORT SWING.

Joaquín Darío Huertas Ruiz'

Resumen

El juego y el deporte poseen un significativo correlato como actividades humanas por cuanto son reflejo de la espiritualidad y cotidianidad. En este escrito se analiza la situación hermenéutica del juego y el deporte a partir de las reflexiones de H.G. Gadamer en "Verdad y Método I" y en "La actualidad de lo bello". También se presentan algunas reflexiones acerca de la dinámica ontológica del juego y la vida cotidiana en el futbol y el ciclismo, a partir de algunos poemas y las obras "El fútbol a sol y sombra" de Galeano y "Los reyes de las montañas" de M. Rendell, con la intención de demostrar la íntima relación que hay entre la espiritualidad y la acción, ya sea como juego de conjunto o como evento individual.

Palabras clave: interpretación, juego, deporte, fútbol, ciclismo.

\section{Abstract}

The games and sports have a significant correlation as human activities because they reflect spirituality and cotidianity. This paper discusses the hermeneutic situation of the game and sport from the work of H.G. Gadamer in "Truth and Method I" and" "Facts about the beautiful". It also discusses some reflections about the ontological dynamic of the game and everyday life in football and cycling, from poems and the plays "Soccer in Sun and Shadow" by Galeano and "The kings of the mountains" by M. Rendell, aiming to evidence the intimate relationship between spirituality and action, either as team game or as a individual condition.

Keywords: interpretation, play, sport, football, cycling.

Fecha de recepción: 5 de junio de 2011

Fecha de aprobación: 5 de octubre de 2011

1 Magister en Filosofía Latinoamericana, USTA. Especialista en Investigación Social, UPN. Licenciado en Filosofía e Historia, USTA. Estudiante del Doctorado Interinstitucional en Educación UPN. Docente del Departamento de Ciencias Sociales UPN. Correo electrónico: daríohuertas@gmail.com. 
Jugar es la manifestación fundamental de la existencia humana. En su dinámica, el ser puede expresar en plenitud la lucha, el amor, el trabajo y la muerte, sin temor a la pérdida de sí mismo en el desierto de la vida cotidiana. Esta experiencia se extiende en el espectro de la relación con el mundo, de manera tan excepcional, capaz de convertirse en un enlace posible para encontrarse en el otro a través de la vivencia dialógica de lo lúdico (Ver Fink, 1995).

No sólo podemos afirmar juego, luego soy; también podemos afirmar jugamos, luego somos, en tanto las prácticas lúdicas deportivas vinculan al deportista y al aficionado en la participación de una naturaleza muy especial en el jugar, tan significativa en la vida actual que convierte los juegos y los deportes en uno de los motores de la economía y la cultura. Existen varios canales de televisión exclusivamente de deportes, que ofrecen la transmisión de competencias en todo el mundo y de gran variedad de disciplinas. Es factible recrearse ahora con alguno de los videojuegos que reproducen virtualmente cualquiera de los deportes modernos; algunos usan como personajes las imágenes de los deportistas más importantes. En la red mundial de la información, los vínculos sobre deportes se cuentan en miles de millones y las regalías por este sector del entretenimiento hacen palidecer fácilmente a cualquiera que diga que el deporte es insignificante (Ver Cagigal, 1957).

¿Por qué la gente disfruta tanto de ver jugar? ¿Existe algo realmente significativo en la experiencia de seguir una competencia deportiva o aquello solo es producto del delirio y la alienación masificada de la industria? (Ver Gadamer, 1991: 31-39)

¿Por qué algunas obras de importantes escritores manifiestan tal obsesión por el deporte o sencillamente usan del deporte y el juego para hacer el respetable entretenimiento que significa el arte? Desde la antigüedad, el juego y el deporte han sido materia prima para la creación de arte, sobre todo de literatura. Podemos mencionar a los griegos Homero y Píndaro, quienes en sus obras incluyeron juegos y prácticas deportivas; también caben los mitos mesoamericanos donde el juego y el deporte tienen valor sagrado y cósmico. En nuestros tiempos más cercanos, son varios los escritores que han hecho con el juego y los deportes una valoración de la vida y la existencia: Borges, Cortázar, Galeano, Vargas Llosa, y una larga lista de autores han hecho de su visión del juego un enfoque de la propia vida.
¿Existe en la contemplación lúdica del juego la misma trascendencia que se manifiesta en el jugar mismo? Los términos de pasión, amor, fascinación y otras tantas expresiones de la emocionalidad despiertan al ver, escuchar o imaginar los encuentros en el estadio, en la radio o en la crónica. La trasmisión radial de la justa deportiva despierta no pocas emociones entre los seguidores del fútbol y el ciclismo en las épocas del apogeo de la radio: el grito herido de los narradores deportivos pintaba con palabras las acciones atléticas, las jugadas, las estrategias y las reacciones de los jugadores. Los cronistas deportivos y los fotógrafos trataban de capturar el momento decisivo en que se pateaba el balón, cuando el atleta alcanzaba la meta o el púgil noqueaba a su contrincante. Para muchos, el desempeño de los jugadores en la cancha, descrito a grito furioso por narradores deportivos, quienes hacían vibrar los parlantes con sus odas futbolísticas, se convirtieron luego en las reminiscencias de aquellos años gratos de la niñez (Ver Villoro, 2006: 69-71).

¿Por qué la finta, la ruptura de la marca, el sufrimiento del deportista que enfrenta la adversidad se adentra en nosotros hasta hacernos saltar el corazón de emoción? (Ver Gumbrecht, 2006: 39)¿Encontramos en el deporte profesional, el de los records y el rendimiento superior, por ejemplo el fútbol y el ciclismo, los reflejos de la dicha que proporciona a la existencia el jugar?

Tenemos dos situaciones perfectamente distintas aunque parten del mismo origen: disfrutamos de ver jugar, que por alguna razón es vital para la existencia del observador; pero a partir de ello mismo se intenta reflejar el mundo del juego, convirtiéndolo en mito, poema, obra literaria... En ambas situaciones la existencia atraviesa los límites de la propia experiencia y se adentra en la vida jugada de los otros donde se encuentra otro juego entre el jugador y el observador.

El poema Fútbol de Blanca Varela nos inicia en esta relación entre el juego observado y el observador: mundo y vida se manifiestan con extrema sencillez y en perfecta concordancia cuando se comprende que la vida se juega de tantos modos y la alegría tiene la sencilla imagen de un niño jugando en el jardín:

Juega con la tierra

como con una pelota

báilala

estréllala

reviéntala 
no es sino eso la tierra

tú en el jardín

mi guardavallas, mi espantapájaros

mi Atila, mi niño

la tierra entre tus pies

gira como nunca

prodigiosamente bella (Varela, 1996)

¿Por qué es posible tal construcción a partir de algo tan simple como un juego infantil? La belleza del poema nos ubica en la poderosa imagen de un niño jugando, como lo hizo también Heráclito en su momento, en el parágrafo 52 (Eggers \& Juliá, 1978). Si jugando nos hemos encontrado con la dinámica fundamental de la existencia, cuando se ve jugar, encontramos un disfrute similar al momento en que jugamos. Jugar desde esta perspectiva será entonces la trascendencia que penetra en otra existencia y se transporta a lo otro existente en medio del sinsentido y la soledad de las que se cuida el hombre para mantener su existir.

\section{Gadamer: el jugar como principio de la interpretación}

Para Gadamer, jugar es la vía para acceder a la ontología de la obra de arte (Ver Gadamer, 1988). Su pregunta sobre la estética lo llevará a preguntarse sobre la dinámica que permite la relación entre obra de arte e intérprete. Se sabe que en la comprensión de las obras artísticas $-y$, en general, de toda obra-, se establece una relación peculiar entre el exégeta y la creación. En esta relación, existe una pugna entre el que pretende comprender y la obra de arte, una creación que expresa una realidad de manera original y diversa y una existencia intentando comprenderse en el mundo y en lo que le proporciona significado a éste.

Gadamer busca resolver esta cuestión tratando de comprender fenomenológicamente al juego. Inicialmente lo analiza como un objeto óntico, quitándole el carácter subjetivo desde el cual se había venido considerando, como dependiente del sujeto que lo juega: Cuando consideramos el jugar, no podemos entenderlo como el desempeño del jugador sino como el desempeño del jugador en el juego. La consideración subjetiva en la que el juego es del jugador niega una de las características que hemos mencionado ya, el ser es una intencionalidad distinta y divergente de la realidad. Tal interpretación está condicionada por el propio modo de ser de la obra de arte. El intérprete es poco libre dentro de las posibilidades ofrecidas por la creación artística. En la interpretación de la obra de arte, prima ésta sobre el intérprete en tanto la creación es un objeto independiente, que tiene su esencia propia y quien lo analiza trata de poder comprenderlo a pesar de las limitaciones que le son propias al intérprete.

El juego aquí establecido es el de las escondidas: el significado se oculta a quien quiere comprenderlo y sólo se le manifiestan algunos indicios parciales que ayudan a dilucidarlo. Aquí podríamos encontrar la fascinación que ejerce la obra sobre el aficionado al arte: es el vaivén de la interpretación en quien disfruta de la obra de arte: encuentra un detalle en la pintura, descubre variaciones entre las interpretaciones musicales un detalle lleva a otro y el conjunto se transforma, se descubre, poco a poco.

Tal dinámica nos sirve para poder comprender las actitudes del espectador que contempla un juego y al hincha que devotamente apoya a su equipo, así como también al simple observador que juzga al deporte como algo bello y sublime. Si objetivamos el juego, nos damos cuenta que este tiene su propia esencia: está en la identidad que le proporcionan las reglas y en el modo como es pleno movimiento dinámico de la existencia. Ante el juego ajeno, sobre todo ante el deporte jugado por deportistas profesionales, nos encontramos en el ideal de lo que esperamos ver y de lo que tenemos ante nosotros.

El vaivén entre el espectador y los jugadores, es un intercambio fundamental entre el público que espera ver el juego y su desenvolvimiento óptimo, en su propia identidad. Esa confrontación de voluntades, la del expectante observador y la del jugador que juega su juego, tendrá la esencia de la cuestión. En ambos está presente la realización de los objetivos del juego y, el segundo, quien juega, tendrá la posibilidad de cumplir tal objetivo, buscando gozar la ejecución de tal acción, cosa que el primero, el aficionado, identificará como la realización de su disfrute o en el caso de la pérdida, su tristeza, tal como sucede en la obra de arte, donde el pintor o el ejecutante, se expresan y producen la comunicación de tal realidad. En la obra de teatro, la ejecución del actor podrá ser buena o mala, de acuerdo al modo en que está sujeto al juego estricto que le impone el libreto, teniendo algunas variaciones con las cuales puede jugar, pero estas serán muy restringidas en tanto el libreto ha definido el rumbo que toma la acción representada.

En el fútbol y en otros deportes de conjunto, la virtud del jugador dentro del juego será eso que busca 
el observador. El movimiento de la esfera conducida por los pies no sólo es armonioso y bello en sí mismo, sino que la manera en que se da el movimiento habrá belleza y admiración por parte de los quienes ven el desenvolvimiento del juego. El vaivén entre lo que se espera y lo que sucederá, tal vez sea lo que despierta la fascinación del aficionado -o el fanático-- y sea el juego que éste va a jugar al estadio.

El futbol nos da la oportunidad de interpretar lo que verdaderamente sucede en el juego entre el jugador y el juego que ve jugar (Ver Gadamer, 1988: 148-149): Latinoamérica se ufana de tener los mejores futbolistas del mundo. Son estos jugadores los que, mediante su ejecución sublime, quienes hacen del juego una experiencia significativa y superior para la vida de todos aquellos que gustan del fútbol. Pero veremos que no son sólo los jugadores los que van a manifestar la belleza sublime del juego sino también el resultado que se espera, el gol, así como también del observador que juega su juego de devoción, alegría, tristeza y locura dentro de la cancha. Es curioso cómo el flujo de la vida entra y sale del juego, como esparcimiento y solaz, pero también como profesión y meta, como ideal. Trataremos de comprender cómo la vida se desenvuelve junto a la vida de otros.

\section{El mayor espectáculo del mundo.}

Jugar es estar en la frontera de la alegría y la tristeza. Jugar es vivir... (Valdano, 2002, p. 108)

Dentro de la dinámica interpretativa, el debate entre lo construido y lo esperado por el espectador y lo jugado por el atleta ¿Cuál es el encanto de eso que llamamos fútbol? ¿Se puede entender este fenómeno desde sus elementos, el gol, el hincha, el jugador? Cuando tratamos con un espectáculo que en su momento cumbre es seguido por miles de millones de espectadores, podemos intuir que existe en él alguna cosa que provoca la adhesión casi religiosa por parte de sus aficionados, que bien vale la pena analizar cuál es su embrujo, su juego. Como nos hemos empeñado en la tarea de comprender cómo se desenvuelve el juego en el que lo disfruta desde las gradas del estadio o frente a la pantalla del televisor, debemos comenzar a jugar con creaciones que sus aficionados han confeccionado, centrándonos en este caso en la obra de Eduardo Galeano, "El futbol a sol y sombra", quien en una serie de relatos breves, nos ilustra critica y líricamente sobre el deporte rey.

\section{El gol}

El gol es el orgasmo del fútbol. Como el orgasmo, el gol es cada vez menos frecuente en la vida moderna. Hace medio siglo, era raro que un partido terminara sin goles: 0 a 0 , dos bocas abiertas, dos bostezos. Ahora, los once jugadores se pasan todo el partido colgados del travesaño, dedicados a evitar los goles y sin tiempo para hacerlos.

El entusiasmo que se desata cada vez que la bala blanca sacude la red puede parecer misterio o locura, pero hay que tener en cuenta que el milagro se da poco. El gol, aunque sea un golecito, resulta siempre go0000000000000000000000ol en la garganta de los relatores de radio, un do de pecho capaz de dejar a Caruso mudo para siempre, y la multitud delira y el estadio se olvida de que es de cemento y se desprende de la tierra y se va al aire (Galeano, 1995, p. 9).

¿Se puede comprender la parte, el gol, por el todo, el fútbol, que a veces es el comienzo, la ilusión o el final dramático de una tragedia griega? Físicamente, un gol no es más que un balón cruzando un espacio demarcado como meta; desde los términos de la competición, es aquello que ofrece el resultado de un partido; al ser tan común en nuestro contexto el futbol, es casi seguro que sepamos la emoción desatada por hacer un gol, podemos comprender el sentido del instante que a algunos les convierte en dioses la memoria y el alma; podemos saber entonces que ese dato indicador involucra no sólo el tiempo y la condición presentes, sino que son detonantes de estados de ánimo que matizan la vida misma del jugador y del hincha. Es significativo que este mismo evento puede producir una emoción y un sentido contrario, convirtiéndose en tristeza y decepción, presentes con más fuerza en la memoria deportiva.

¿Será posible tratar de descifrar la epifanía religiosa del juego en la jugada no esperada que se convierte en el orgasmo de la larga espera del aguante o en la impotencia del gol en contra o en su misma ausencia?; rara religión en la que el destino aún no está escrito por el dios, quien a veces desvía el tiro y deja a los fieles con el sabor amargo de la frustración en la garganta, con la bola perdida entre los anuncios publicitarios.

Pero el fútbol no es sólo el gol. El fútbol es mucho más que eso; es el camino hacia la trascendencia de la emoción. El fútbol se ha convertido es una vivencia que compromete el ser y hace parte del transcurso histórico de la vida, que se conduce con los pies y permanece ante todas las decisiones y vicisitudes que la vida y los 
campeonatos imponen -afortunadamente o no- al aficionado y al jugador.

El jugador, pateando el balón u oponiéndose al contrario que lo tiene está haciendo mucho más que eso, se está jugando la vida a las patadas, en la calle del barrio o en el Maracaná, está viviendo un estado épico; el juego es un asunto de lo más serio para el jugador porque pone en movimiento su vida junto a los otros con quienes vive y contra quienes lucha.

La virtud en el movimiento, la gambeta imposible y la patada en el punto adecuado despiertan las más hondas emociones de la raíz del juego, cuyo culmen debería terminar en gol. Tal gesta despierta en el espectador la motivación necesaria para querer manifestar su percepción de la belleza deportiva, como lo hace Vinicius de Moraes:

O Anjo de Pernas Tortas

A um passe de Didi, Garrincha avança

Colado o couro aos pés, o olhar atento

Dribla um, dribla dois, depois descansa

Como a medir o lance do momento.

Vem-lhe o pressentimento; ele se lança Mais rápido que o próprio pensamento, Dribla mais um, mais dois; a bola trança Feliz, entre seus pés - um pé de vento!

Num só transporte, a multidão contrita Em ato de morte se levanta e grita Seu uníssono canto de esperança.

Garrincha, o anjo, escuta e atende: Goooool! É pura imagem: um G que chuta um 0 Dentro da meta, um L. É pura dança! (Garcí Candau, 1996, p. 326)².

Pero, ¿se juega solamente en la cancha? ¿Está el encanto del fútbol en la ejecución o también en la contemplación del movimiento? La belleza del fútbol sería razón

2 "A un pase de Didí, Garrincha avanza/ con el cuero a los pies, el ojo atento,/dribla una vez, y dos, luego descansa/cual si midiera el riesgo del momento. Tiene el presentimiento, y va y se lanza/más rápido que el propio pensamiento, /dribla dos veces más, la bola danza/feliz entre sus pies, ¡los pies del viento! En éxtasis, la multitud contrita,/en un acto de muerte se alza y grita/en unísono canto de esperanza. Garrincha, el ángel, oye y asiente: ¡Goooool!/Es pura imagen: la $\mathrm{G}$ chuta la O/dentro del arco, la L. / ¡Es pura danza!". suficiente para justificar su valor existencial, pero necesariamente debe extenderse la significación vital del juego a la experiencia vivida por quien contempla el juego. El juego en las graderías es distinto al de las canchas y las emociones y situaciones del partido se leen como la vida misma, pues en ésta también le meten a uno goles. Pasemos por las graderías del estadio para contemplar al hincha:

\section{El hincha}

Una vez por semana, el hincha huye de su casa y asiste al estadio.

Flamean las banderas, suenan las matracas, los cohetes, los tambores, llueven las serpientes y el papel picado; la ciudad desaparece, la rutina se olvida, sólo existe el templo. En este espacio sagrado, la única religión que no tiene ateos exhibe a sus divinidades. Aunque el hincha puede contemplar el milagro, más cómodamente, en la pantalla de la tele, prefiere emprender la peregrinación hacia este lugar donde puede ver en carne y hueso a sus ángeles, batiéndose a duelo contra los demonios de turno.

Aquí, el hincha agita el pañuelo, traga saliva, glup, traga veneno, se come la gorra, susurra plegarias y maldiciones y de pronto se rompe la garganta en una ovación y salta como pulga abrazando al desconocido que grita el gol a su lado. Mientras dura la misa pagana, el hincha es muchos. Con miles de devotos comparte la certeza de que somos los mejores, todos los árbitros están vendidos, todos los rivales son tramposos.

Rara vez el hincha dice: "hoy juega mi club". Más bien dice: "Hoy jugamos nosotros". Bien sabe este jugador número doce que es él quien sopla los vientos de fervor que empujan la pelota cuando ella se duerme, como bien saben los otros once jugadores que jugar sin hinchada es como bailar sin música.

Cuando el partido concluye, el hincha, que no se ha movido de la tribuna, celebra su victoria; qué goleada les hicimos, qué paliza les dimos, o llora su derrota; otra vez nos estafaron, juez ladrón. Y entonces el sol se va y el hincha se va. Caen las sombras sobre el estadio que se vacía. En las gradas de cemento arden, aquí y allá, algunas hogueras de fuego fugaz, mientras se van apagando las luces y las voces. El estadio se queda solo y también el hincha regresa a su soledad, yo que ha sido nosotros: el hincha se aleja, se dispersa, se pierde, y el domingo es melancólico como un miércoles de cenizas después de la muerte del carnaval. (Galeano, 1995, p. 7) 
Aquí ha pasado algo, y es que el fútbol adquiere sentido como un drama a interpretar, con goce y sufrimiento, en la impotente intención de ver vencedor al equipo de los amores. El espectador, quien va al estadio con la camiseta o se sienta frente al televisor para ver el partido, es quien otorga un sentido a la brega de veintidós hombres divididos en dos equipos quienes se oponen por acumular puntos a favor y evitar los puntos en contra. Para el hincha, él es en tanto su equipo juega, porque está en juego su vida, el contenido significativo de la vida, ya sea feliz por el triunfo o apenas soportable porque el equipo no gana nunca.

El fútbol, como todo juego, no es ninguno de los elementos con que se juega, es decir, el balón, la cancha o la camiseta; tampoco es los sentimientos que genera, sino el encontrarse jugando fútbol, ya sea como espectador o como jugador. Es un estado actual del hombre, poseído por la acción y la emoción, apareciendo en el todo y en la parte, que no se puede entender sin ésa relación circular unida por el milagro del frenesí concordante en el sentido común de la expectativa de la experiencia trascendente del triunfo.

\section{El juego y la vida. El deporte como reflejo de la realidad de un pueblo}

En el vaivén entre la emoción sentida por el aficionado y la vivencia ejercida por el equipo de los amores existe una cierta comunión casi evidente entre ambos actores; el jugador juega y el aficionado es capaz de hacer memoria de algo vivido colectivamente. Pero en el caso de deportes como el ciclismo, ¿qué mueve a seguir una carrera ciclística? ¿Existe la misma participación, es decir, igual identificación vivencial-existencial entre los corredores y los aficionados al ciclismo, como sucede en el fútbol? ¿Cuál es el disfrute del fanático, quien sigue emocionadamente la narración de la etapa? ¿Qué refleja de nuestra vida la actitud del ciclista sobre su caballito de acero, que nos atrae y fascina?

Las competencias ciclísticas son por completo distintas a las futbolísticas; si en el fútbol la jugada y el gol devienen en epifanía y misterio, en la jornada ciclística el sacrificio y el esfuerzo hacen lo propio. Joaquín Marta Sosa ilustra bellamente en los gestos del atleta el sufrimiento intrínseco de la vida, asumido duramente en la cotidianidad. El esfuerzo y el valor de la faena imposible, la vivencia del dolor sobre dos ruedas donde el sacrificio se une a la pérdida permanente de energías, a la soledad que implica la conducción de este vehículo.
El ciclista conquista la ruta o la cuesta, pero antes conquista a la bicicleta como primer objeto; impone una previa doma, la del equilibrio, y luego el dominio sobre la distancia y el ángulo, lo que implica abnegación en el largo entrenamiento necesario para ello. Quien contempla tal proeza, ¿acaso vivencia en si mismo tal sufrimiento, se solidariza con el rictus de dolor o se encuentra identificado con la esencia de la faena de conquista? Hemos de notar que el arte del poeta interpreta fielmente aquella situación de juego, pues padece con el corredor su gesta. ¿Su decir, aparentemente inofensivo y devenido en arte, logra participar del pathos de la vida sobre las dos ruedas del destino?

\section{El ciclista}

El ciclista va crucificado hacia lo alto de la montaña atrás kilómetros y kilómetros de carreteras ya no suda agotada el agua toda de su cuerpo el sudor lo inunda como un caballo enloquecido no mira sus piernas son los ojos tampoco oye concentrado va en su corazón en la oscuridad de los pulmones agoniza combaten, (...)

yo: cercado entonces por el terror de los derrumbes con un temblor de pesadilla presumo la meta muy lejana mi cara tras la ventanilla del carro que acompaña hago mío ese cuerpo desecho en una vida agigantada llamarada que se extingue y se rebela

(...)

porque es un cazador solitario el ciclista

a la caza de sí mismo

que puede morir y muere

en las tenazas de un silencio donde la compasión se ahoga cuando la gente grita contra sus ojos ciegos

contra sus oídos muertos

no te rindas

queriendo decir no nos abandones olvida tu desamparo por nosotros sueña con la tentación de un barco a la deriva fuera lejos muy lejos de este mundo (...)

el ciclista sigue continúa en la cárcel de sí mismo salvo al orgullo limpio y cruel

de quienes lo idolatran hasta el fin consumado él en su destino esa amistad mortal que lo reta y que él no desafía que jamás traicionará ni siquiera si con la muerte tiene que entendérselas entregándose entero a sus cuchillos 
y desde allí vencerla

a pesar de la derrota. (Marta Sosa, 1999)

Ciclista y aficionado celebran una suerte de viacrucis non sacto, una epopeya: "Como en la Odisea, la carrera es a la vez un periplo de pruebas y exploración total de los límites terrestres. Ulises alcanzó varias veces las puertas de la tierra (...) Como en la Odisea, la carrera es a la vez un periplo de pruebas y exploración total de los límites terrestres. Ulises alcanzó varias veces las puertas de la tierra" (Barthes, 1980, p. 118). A diferencia de las sagas literarias, la prueba no es sólo el recuento de lo que pasó, sino la vivencia de la cual son testigos sus destinatarios, quienes en el relato necesitan hacer uso de su imaginación para re-vivir y celebrar lo alcanzado, mientras tanto, en la gesta deportiva, el observador sabe cómo se desenvuelve la hazaña y puede ofrecer su parte de la oblación en la superación del desafío. El drama del ciclista se convierte en deseo del espectador por ser parte del impulso del atleta, quiere otorgarle un poco de su espíritu para contrarrestar el dolor del sacrificio de quien osa enfrentar los elementos contra la naturaleza misma del equilibrio elemental.

La montaña, esa fuerza inconmensurable, no será solamente vencida por el lote de corredores, sino también por quienes los acompañan al lado de las vías y con el oído pegado al radiotransmisor. Tanto el deportista como el aficionado son capaces de objetivar la etapa, la convierten en un ser, un monstruo que espera vencerles con cansancio y abandono; los ciclistas vienen a ser quijotes en armadura de lycra y huesudo rocinante de acero. El aficionado necesita saber que la naturaleza puede ser vencida de tal manera heroica, natural, primitiva, como lo son sus más humanos instintos. Un tanto de ello sucederá en nuestro país, donde el ciclismo es el deporte nacional. En "Los reyes de las montañas", de Matt Rendell, el silencioso e imperceptible oscilar del ciclista va a retratar el curso de la realidad de la nación colombiana: Uno de los momentos más importantes es la saga de Lucho Herrera en el Tour de France de 1985, durante la etapa en St. Etienne:

A la cabeza en el último descenso, Lucho Herrera resbaló y cayó. La sangre corría por su rostro cuando, cojeando, cruzó la raya para ganar la etapa. El viento formaba pequeños arroyos de sangre que rodaban por su cara. Segundos después, Hinault se estrelló contra otros corredores y cayó de cabeza contra el asfalto. Con la nariz fracturada, los ojos ennegrecidos y el cráneo sangrando, también cruzó la raya a gatas. Herrera no supo del accidente de Hinault sino hasta que se encontraron en el hospital.
(...)En el cuerpo pequeño, el rostro ensangrentado y la victoria tormentosa de Lucho, Colombia se vio reflejada con más fidelidad que nunca. (Rendell, 2004: 274)

Además del horror de sus violencias armadas, la épica ciclística ha marcado la identidad de los colombianos por los resultados obtenidos y por el modo como se ha desarrollado este deporte en nuestro país, paralelo al devenir de nuestra historia más reciente. Hasta hace muy poco, la vuelta a Colombia era el evento deportivo más importante del país y es, de hecho, uno de los pocos sucesos que congrega a prácticamente todos los colombianos. De esta vuelta, iniciada en 1951, podemos afirmar que fue la primera gran hazaña deportiva nacional, comparable con la empresa de conquista española, pues se fue desarrollando como una batalla contra los elementos, con la misma violencia con que en ésos momentos se pelea en los campos y aparecen los gérmenes de lo que será el conflicto actual.

En nuestro país, la facticidad del ciclista es la misma del campesino luchando contra la adversidad de la geografía del terreno. Nuestra nación se ha desarrollado prioritariamente en la montaña: sobre los Andes encontraremos las mayores concentraciones de población colombiana y también a quienes irracionalmente van a desafiar la titánica cordillera con las delgadas máquinas con motor a sangre. El autor inglés reconoce en el sacrificio extremo del "jardinerito" el esfuerzo de la vida de los colombianos, quienes enfrentan la furia de su destino histórico y lo superan con un estoicismo propio del Ecce homo, simbolizado en el Jesús caído de Monserrate en Bogotá: la sangre y el movimiento imposible tras la tortura romana de los latigazos son la representación de nuestro sino. Durante el mismo año de la epopeya en Francia, el país enfrentará la hecatombe del Palacio de Justicia en Bogotá y unos días después veinte mil personas desaparecerán ante la ira del Nevado del Ruiz. También en esos días, nuestro país padecerá la violencia del narcoterrorismo y el ocaso del ciclismo en el país, que aún marcan nuestra realidad, como una etapa donde se atraviesa una montaña, con varias caídas incluidas.

La iconografía del Sagrado Corazón, al igual que el Señor Caído de Monserrate, me pareció que contenían aun mas ingredientes para explicar la fascinación colombina por el ciclismo. El afecto que sienten por cristos en agonía y corazones ensangrentados predispone a los colombianos a percibir atisbos de salvación en los esfuerzos de los ciclistas [...] Y también el gotea sangre -igual que los ciclistas caídos ha- 
ciendo muecas de dolor desde miles de fotografías de las competencias, fieles en sui devoción- y promete que el premio sólo será recibido tras la más cruel de las abstinencias. (Rendell, 2004: 57)

Parte del encanto del ciclismo estará en su capacidad de compartir las mismas situaciones trascendentales con la vida cotidiana: esfuerzo, sufrimiento, abnegación sacrificio, inconformidad ante el destino. Tales implicaciones interpretativas nos impulsan a preguntarnos en las dos orillas de la interpretación ¿Por qué la existencia se desenvuelve de modo paralelo en la vida y en el juego? Porque aquí se configura la ubicación de la vida y el juego en el tiempo y el espacio que le corresponden en el jugar, y en el deporte el espacio y el tiempo se desarrollan de modo distinto al tiempo de la percepción física. La primera vuelta a Colombia se hizo luego de evidenciar que sí era posible hacerla en 1951, cuando la infraestructura vial era un chiste de mal gusto. Tal hazaña era posible por un monarca de la bicicleta, un Zipa:

Cuando empecé a correr en bicicleta, en 1949, intentaba leer todo lo que podía. Obviamente, leí sobre el Tour de France y la mitología en torno a los Alpes y los Pirineos. Pensé para mis adentros: con una geografía como la nuestra, una Vuelta a Colombia sería algo extraordinario.

Quienes lo cuestionaban declararon la idea como un sueño irrealizable. Aun en el caso de que las carreteras fueran por lo menos carreteables, la topografía y la altitud extrema eran suficientes para hacer físicamente irrealizable semejante empresa. Es lo que indicaba el sentido común y también la historia. (Rendell, 2004: 22)

La vida de todos los días estará atravesada por el encanto y el gozo que el deporte va a inspirar en las personas que siguen las vicisitudes de las competencias, su indeterminación, la libertad de realización, de cara a la monotonía de las arenas permanentes del desierto cotidiano. En la bella danza de los pases y gambetas del futbolista, y en los golazos estará la alegría y la necesidad de enarbolar la camiseta como una bandera, también la pena cuando el equipo siempre pierde. Igualmente, el supremo esfuerzo deportivo, que a veces se da en medio del hambre, hincha el corazón de júbilo, cuando se pasa la meta, porque sabemos que ése deportista es un hombre como nosotros superando un desafío mayor a nosotros mismos. La vida se interpreta a sí misma en el juego y se aprende a vivir jugando, porque la vida es precisamente un constante jugar con el tiempo, el trabajo, el amor, la muerte. Quien ve jugar comparte la vida alegremente vivida y espera encontrar tal gozo en estos instantes fugaces que plenifican la existencia.

\section{Referencias}

Barthes, R. (1980) In J.-J. Barreau \& J.-J. Morne (Eds.) Epistemología y antropología del deporte (p. 118). Madrid: Alianza Editorial.

Cagigal, J. M. (1957) Oh! Deporte. Anatomía de un gigante. Madrid: Taurus.

Eggers, C., \& Juliá, V. (1978) Los filósofos presocráticos. Madrid: Gredos.

Fink, E. (1995) Fenómenos fundamentales de la existencia humana. (C. Hozapfel, Trans.). Friburgo: Karl Alber.

Gadamer, H.-G. (1988) Verdad y Método. Fundamentos de Hermenéutica filosófica. Salamanca: Sígueme.

Gadamer, H.-G. (1991) La actualidad de lo bello (1ํㅗ ed.). Barcelona: Paidós.

Galeano, E. (1995). El fútbol a sol y sombra (4ํㅡㄹ ed.). Buenos Aires: Siglo XXI.

García Candau, J. (1996) Épica y lirica del fútbol. Madrid: Alianza editorial.

Gumbrecht, H. U. (2006) Elogio de la belleza atlética. Buenos Aires: Kats Editores.

Marta Sosa, J. (1999) El ciclista Territorios Privados: Monte Avila editores.

Rendell, M. (2004) Reyes de las montañas: cómo los héroes del ciclismo colombiano incidieron en la historia de su país. Bogotá: Grupo Editorial Norma.

Valdano, J. (2002) El miedo escénico y otras hierbas. Madrid: Santillana Ediciones.

Varela, B. (1996) Canto villano: poesía reunida, 19491994: Fondo de Cultura Económica.

Villoro, J. (2006) Dios es redondo. Bogotá: Editorial Planeta. 